\title{
CD44-Targeted Magnetic Nanoparticles Kill Head And Neck Squamous Cell Carcinoma Stem Cells In An Alternating Magnetic Field
}

This article was published in the following Dove Press journal: International Journal of Nanomedicine

\author{
Zhan Su $\mathbb{1}^{1,2}$ \\ Duanqin Liu ${ }^{1,2}$ \\ Liying Chen ${ }^{2}$ \\ Jun Zhang ${ }^{1,2}$ \\ Lu Ru ${ }^{2}$ \\ Zhiyu Chen ${ }^{2}$ \\ Zhennan Gao (D) ${ }^{1,2, *}$ \\ Xuxia Wang ${ }^{1,2, *}$
}

'Shandong Provincial Key Laboratory of Oral Tissue Regeneration \& Shandong Engineering Laboratory for Dental

Materials and Oral Tissue Regeneration, Jinan, Shandong 2500I2, People's

Republic of China; ${ }^{2}$ Department of Oral and Maxillofacial Surgery, School of

Stomatology, Shandong University, Jinan, Shandong 250012, People's Republic of China

*These authors contributed equally to this work
Background: Head and neck squamous cell carcinoma (HNSCC) is the sixth most common malignant tumor in the world. Studies in recent years have demonstrated that cancer stem cells (CSCs) are present in many tumor tissues, including HNSCC, and CSCs are the root cause of tumor recurrence and metastasis. Thus, taking new treatment measures to target the killing of CSCs that are resistant to chemotherapy and radiotherapy is key to the success of cancer treatment.

Methods: We explored a method for preparing anti-CD44 antibody-modified superparamagnetic iron oxide nanoparticles (SPIONPs). Biocompatibility was evaluated by a CCK-8 assay. The CSCs were obtained by a 3D cell culture technique from Cal-27 (human oral squamous cell carcinoma) cells, and then the CSCs were identified by quantitative real-time polymerase chain reaction (qRT-PCR). The targeting efficiency of the CD44-SPIONPs to CSCs was confirmed by Prussian blue staining and visualized by laser scanning confocal microscopy (LSCM). Flow cytometry was used to detect the apoptosis of CSCs after alternating magnetic field (AMF) treatment. The efficacy of tumor growth inhibition by CD44-SPIONP-mediated magnetic hyperthermia therapy was evaluated with tumor xenografts in nude mice.

Results: The CD44-SPIONPs exhibited no negative effect on CSCs, indicating good biocompatibility. After SPIONPs were cocultured with stem cells, the majority of CD44SPIONPs labeled with FITC penetrated the cell membrane into the cytoplasm. After AMF treatment, CD44-SPIONPs induced CSCs to undergo programmed death. The inhibitory ratio of the treated group was $33.43 \%$, and necrotic areas in the tumor tissue were mainly distributed around the magnetic fluid.

Conclusion: These results demonstrate that it is possible to kill CSCs using targeted magnetic nanoparticles and an AMF and that magnetic fluid hyperthermia significantly inhibited the growth of grafted Cal-27 tumors in mice.

Keywords: magnetic nanoparticles, cancer stem cells, alternating magnetic field, tumor targeting

\section{Introduction}

Xuxia Wang

Department of Oral and Maxillofacial

Surgery, School of Stomatology, Shandong

University, 44-I West Wenhua Road,

Jinan, Shandong 250012, People's Republic

of China

Tel +86 53I 1516907089I;

$+8653113906410670$

Email zngao@sdu.edu.cn;

wxx@sdu.edu.cn
Surgery, chemotherapy, and radiotherapy are still common methods for the treatment of HNSCC. However, the side effects of radiotherapy and chemotherapy seriously affect the quality of life and survival time of patients. ${ }^{1,2}$ Therefore, it is imperative to research and develop a more effective, safe, and minimally invasive or noninvasive HNSCC treatment method. Studies in recent years have demonstrated that CSCs are present in many tumor tissues, including HNSCC. ${ }^{3-5} \mathrm{CSCs}$ 
are a group of cells within the whole population of cancerous cells that are capable of self-renewal and both sustain tumorigenesis and cause metastasis. Moreover, large numbers of CSCs accumulate in tumor tissues after chemotherapy and radiotherapy. ${ }^{6,7}$ Developing new therapeutic measures that kill CSCs that are resistant to chemotherapy and radiotherapy is the key to the success of cancer treatment.

Traditional tumor hyperthermia has played an important role in the treatment of cancer, but these traditional thermotherapy techniques cannot effectively kill CSCs. ${ }^{8}$ Although nanoparticle-mediated laser hyperthermia can kill CSCs, laser hyperthermia is generally suitable for the treatment of only superficial tumors. ${ }^{9}$

The principle of magnetic fluid hyperthermia is to use magnetic nanoparticles under an alternating magnetic field (AMF) to generate heat through magnetic vector rotation and physical rotation. Magnetic fluid containing magnetic nanoparticles can be administered through a tumor-feeding artery or by direct injection. ${ }^{10}$ After reaching the inside of the cells by endocytosis, under the external AMF, a hightemperature zone is quickly formed inside the tumor to achieve the effect of killing tumor cells or inducing apoptosis while preventing the normal surrounding tissues from being heated.

Sadhukha's research demonstrated that SPIONP-mediated hyperthermia therapy can kill CSCs. ${ }^{11}$ However, there is currently no study of targeted magnetic fluid hyperthermia for CSCs. With in-depth study, some characteristic surface marker proteins of CSCs have been verified. The discovery of these surface markers enables the enrichment, identification, and targeting of CSCs. ${ }^{12,13}$ CD44 is a cell-surface glycoprotein that plays a role in cell adhesion and migration, serves as a receptor for hyaluronic acid and interacts with other ligands, such as osteopontin, collagen, and matrix metalloproteinases. ${ }^{14,15}$ CD44 participates in a wide variety of cellular functions, such as lymphocyte activation, recirculation and homing, hematopoiesis, and tumor metastasis. ${ }^{16,17}$ Herein, we demonstrate the possibility of targeting CD44overexpressing CSCs with CD44-SPIONPs and applying magnetic fluid hyperthermia.

\section{Materials And Methods}

\section{Reagents And Instrumentations}

Fetal bovine serum (FBS), Dulbecco's Modified Eagle's medium (DMEM), Dulbecco's Modified Eagle's Medium/ Ham's Nutrient Mixture F-12 (DME/F12) and phosphate buffer saline (PBS) were purchased from Hyclone (LA, USA). Trypsin-EDTA solution was purchased from Merck KGaA (Darmstadt, Germany). 4-Morpholineethanesulfonic acid hydrate (MES), 1-(3-dimethylaminopropyl)-3-ethyl carbodiimide hydrochloride (EDC) were purchased from Aladdin (Shanghai, China). Mouse Anti Human CD44 FITC (sc-7297) was purchased from Santa Cruz Biotechnology (CA, USA). BCA Protein Assay Kit was purchased from Thermo Fisher Scientific (MA, USA). Epidermal growth factor (EGF) peptide and basic fibroblast growth factor (bFGF) were purchased from PeproTech (NJ, USA). B-27 supplement was purchased from Gibco (CA, USA). Ultra-low attachment multiwell plate was purchased from Corning (NY, USA). Cell Counting Kit-8 (CCK8) was purchased from DOJINDO (Tokyo, Japan). Trizol was purchased from Thermo Fisher Scientific (MA, USA). First strand cDNA Synthesis Kit and SYBR Green I was purchased from Takara Biomedical Technology (Beijing, China). Zetasizer Nano ZSE was purchased from Malvern Panalytical (Malvern, UK).

\section{Cell Lines And Animals}

Cal-27 cells were purchased from the Laboratory Animal Center of Shandong University (Jinan, China). Cells were cultured using DMEM containing 10\% FBS and 1\% of penicillin, and maintained in a controlled atmosphere at $37^{\circ}$ $\mathrm{C}, 95 \%$ relative humidity, and $5 \% \mathrm{CO}_{2}$. The culture medium was changed every three days. The use of cell lines was approved by Ethics Committee of Stomatological Hospital of Shandong University.

Male BALB/c nude mice (4-5 weeks old, about 20g) were purchased from Beijing Vital River Laboratory Animal Technology Co., Ltd (Beijing, China). The use and management of animals was legally acquired and conducted in compliance with the protocol approved by the Ethics Committee of Stomatological Hospital of Shandong University. The maintenance of all the experimental animals that were used in this study was performed according to guidelines of the Institutional Animal Care and Use Committee of Shandong University.

\section{Preparation Of CD44-SPIONPs}

SPIONPs were synthesized by the coprecipitation method, which involves the simultaneous precipitation of $\mathrm{Fe}^{2+}$ and $\mathrm{Fe}^{3+}$ ions in basic aqueous media. Briefly, $10 \mathrm{~mL}$ of 0.05 $\mathrm{mol} / \mathrm{L} \mathrm{FeCl}_{2}, 10 \mathrm{~mL}$ of $0.1 \mathrm{~mol} / \mathrm{L} \mathrm{FeCl}_{3}$ and $50 \mathrm{~mL}$ of $5 \mathrm{~g} / \mathrm{L}$ carboxymethyldextran (CMDx) solution were stirred at 150 $\mathrm{rpm}$ at $80^{\circ} \mathrm{C}$ for $1 \mathrm{~h}$ while adjusting the $\mathrm{pH}$ to $9-10$ by 
adding $\mathrm{NH}_{3} \mathrm{H}_{2} \mathrm{O}$. Meanwhile, deionized water was added to compensate for evaporation. Subsequently, the nanoparticles were washed three times with ethanol (1:3) at 3,500 rpm for $20 \mathrm{~min}$ and dried at room temperature. Carboxymethyldextran-modified magnetic nanoparticles were powdered and kept at $4^{\circ} \mathrm{C} .{ }^{18,19}$

Next, $10 \mathrm{mg}$ of sterilized CMDx-coated nanoparticles were suspended in $0.5 \mathrm{~mL}$ of MES buffer ( $1 \mathrm{~g}$ of MES in $10 \mathrm{~mL}$ of deionized water) by ultrasonication for $5 \mathrm{~min}$, and the solution was adjusted to $\mathrm{pH}$. Then, $0.5 \mathrm{~mL}$ of EDC solution (10 $\mathrm{mg}$ of EDC in $1 \mathrm{~mL}$ of Activation Buffer containing 0.1 M MES and 0.5 M NaCl, pH=6.0) was added, and the reaction was allowed to proceed for 40 min at room temperature. Then, $200 \mu \mathrm{l}$ of $200 \mu \mathrm{g} / \mathrm{mL}$ mouse anti-human CD44 FITC was added and incubated for $18 \mathrm{~h}$ at room temperature in a shaker at $200 \mathrm{rpm}$ while avoiding light. The suspension was centrifuged at 5,000 rpm for $30 \mathrm{~min}$ to obtain the nanoparticles. The CD44 conjugation reaction was reproducible $(3.82 \pm 0.69 \mu \mathrm{g} / \mathrm{mg})$, as determined by a BCA protein assay.

Then, CD44-SPIONPs were suspended in DMEM at a concentration of $5 \mathrm{mg} / \mathrm{mL}$ and stored at $4^{\circ} \mathrm{C}$ for further experiments. $^{20,21}$

\section{Characterization Of Nanoparticles}

The crystalline phase of the SPIONPs was characterized by X-ray diffraction (XRD) measurements. The static magnetic properties of dry SPIONPs and CD44-SPIONPs at room temperature were measured with a vibrating sample magnetometer. The size distribution and morphology of the CD44-SPIONPs were characterized by transmission electron microscopy (TEM). Dynamic light scattering (DLS) curves of the size distribution were obtained using a Nano Sizer.

Meanwhile, the CD44-SPIONPs $(0 \mu \mathrm{g}, 250 \mu \mathrm{g}, 500 \mu \mathrm{g}$, $750 \mu \mathrm{g}$, and $1 \mathrm{mg}$ ) were weighed, and $5 \mathrm{~mL}$ of physiological saline was added to form a magnetic fluid at room temperature. Under a frequency of $273 \mathrm{kHz}$ and an output current of $50 \mathrm{~A}$, the AMF was applied for $30 \mathrm{~min}$, with a fiber-optic temperature sensor to measure and record the temperature and draw the corresponding graph.

\section{D Spheroid Culture}

To obtain tumorspheres, Cal-27 cells were seeded at $1 \times 10^{4}$ cells/mL in DMEM/F12 supplemented with $20 \mathrm{ng} / \mathrm{mL}$ bFGF, $20 \mathrm{ng} / \mathrm{mL}$ EGF, $5 \mu \mathrm{g} / \mathrm{mL}$ insulin, and $0.02 \times$ B-27 supplement in each well of an ultralow attachment multiwell plate in approximately $4 \mathrm{~mL}$. A $1 / 3$ volume of fresh culture medium was added every 3-4 days, and the cells were cultured for approximately 7-10 days. Then, the cells congregated into tumorspheres.

To obtain CSCs, the spheres were allowed to settle by gravity sedimentation for $10 \mathrm{~min}$, and then the supernatant was aspirated. Then, $1 \mathrm{~mL}$ of Trypsin-EDTA solution was added to the tumorspheres, and the spheres were pipetted up and down 10-20 times to generate a single cell suspension. The cells were centrifuged for $5 \mathrm{~min}$ at $300 \mathrm{x} \mathrm{g}$. The supernatant was discarded, and the cells were seeded at $10^{5}$ cells $/ \mathrm{mL}$ in six-well dishes for further experiments. ${ }^{22,23}$

\section{Quantitative Real-Time PCR Analysis}

Total RNA was isolated from Cal-27 cells and CSCs using TRIzol reagent and then reverse transcribed with a reverse transcription kit according to the manufacturer's protocol. The qRT-PCR primers were used to detect the gene expression of Oct4, Sox2, and Nanog, with Gapdh as the reference. The following primer sequences were used: for Oct4, 5'TCAGGAGATATGCAAAGCAGAAAC-3' (forward) and 5'-CTGATCTGCTGCAGTGTGGG -3' (reverse); for Sox2, 5'-GACAGTTACGCGCACATGAA -3' (forward) and 5'TAGGTCTGCGAGCTGGTCAT -3' (reverse); for Nanog, 5'- AGGGTCTGCTACTGAGATGCTCTG -3' (forward) and 5'- CAACCACTGGTTTTTCTGCCACCG -3' (reverse); and for Gapdh, 5'- GCACCGTCAAGGCTGAGAAC -3' (forward) and 5'- TGGTGAAGACGCCAGTGGA -3' (reverse). ${ }^{24}$

\section{Western Blot Analysis}

Cal-27 cells and CSCs were collected and incubated with RIPA buffer. The cell lysate was centrifuged at 12,000 rpm at $4{ }^{\circ} \mathrm{C}$ for $10 \mathrm{~min}$. The supernatant was boiled after adding $5 x$ SDS sample buffer. Proteins were separated using 10\% sodium dodecyl sulfate-polyacrylamide gel electrophoresis for $1.5 \mathrm{~h}$ at $100 \mathrm{~V}$ and transferred onto polyvinylidene fluoride membranes. After blocking with 5\% nonfat milk, the membranes were probed overnight at $4{ }^{\circ} \mathrm{C}$ with primary antibodies, which were rabbit anti-CD44 (1:5,000, Abcam, ab51037) and rabbit anti-Gapdh (1:10,000, Abcam, $\mathrm{ab181602)}$. The membrane was washed and then incubated with HRP-conjugated secondary goat anti-rabbit antibodies (1:10,000, Abcam, ab6721) for $1 \mathrm{~h}$ at room temperature. Target proteins were detected with enhanced chemiluminescence reagents and photographed.

\section{In Vitro Cytotoxicity Study}

The cytotoxicity of CD44-SPIONPs was evaluated using a CCK8 assay. The CD44-SPIONPs were sterilized for $24 \mathrm{~h}$ 
with UV light and then diluted in DMEM before incubation. A total of $5 \times 10^{4}$ cells obtained from spheres were plated into $96-w e l l$ plates and incubated at $37^{\circ} \mathrm{C}$ overnight. Subsequently, the culture medium in each well was replaced with medium that contained CD44-SPIONPs at a series of concentrations and incubated for $24 \mathrm{~h}$ and $48 \mathrm{~h}$. Then, $10 \mu \mathrm{l}$ of CCK8 solution was added to each plate for $2 \mathrm{~h}$. The absorbance was measured at $450 \mathrm{~nm}$ using a microplate reader.

\section{Cellular Internalization Of CD44- SPIONPS}

Loading of CD44-SPIONPs into CSCs was confirmed by Prussian blue staining. Briefly, CSCs were seeded in 24well plates and cultured with DMEM containing CD44SPIONPs at a concentration of $100 \mu \mathrm{g} / \mathrm{mL}$ for $24 \mathrm{~h}$; wells without CD44-SPIONPs were included as the control group. After incubation, the cells were washed three times with PBS. Following fixation for $20 \mathrm{~min}$ in $4 \%$ paraformaldehyde at room temperature, the cells were incubated in a Prussian blue staining solution (1:1 mixture of $1 \mathrm{~mol} / \mathrm{l}$ hydrochloric acid and potassium ferrocyanide) for $30 \mathrm{~min}$ at room temperature. Each well was washed with PBS and analyzed by light microscopy.

For localization measurements, CD44-SPIONPs tagged with FITC were cultured with Cal-27 cells and CSCs, which were seeded on confocal laser dishes at a density of $5 \times 10^{4}$ cells per dish for $24 \mathrm{~h}$ at a concentration of $100 \mu \mathrm{g} / \mathrm{mL}$. After incubation, the cells were washed three times with warm PBS and stained using a $5 \mu \mathrm{g} / \mathrm{mL}$ DAPI solution for 15 min at $37^{\circ} \mathrm{C}$ to stain the cell nucleus. A Carl Zeiss LSM 780 confocal laser scanning microscope was used to visualize nanoparticle interactions with cells. ${ }^{25,26}$

\section{Intracellular Hyperthermia}

To investigate the destructiveness of CD44-SPIONPs to CSCs after AMF treatment, the CSCs were seeded in sixwell culture plates at a density of $1 \times 10^{5}$ cells per well and then incubated with CD44-SPIONPs at a concentration of $100 \mu \mathrm{g} / \mathrm{mL}$ for $24 \mathrm{~h}$. After being washed three times with PBS to remove the free CD44-SPIONPs, the cells were exposed to AMF treatment. The magnetic field was applied for a period of $2 \mathrm{~h}$ at $237 \mathrm{kHz}$ and $50 \mathrm{~A}$. The temperature was monitored using a fiber-optic temperature sensor and maintained between $43^{\circ} \mathrm{C}$ and $45^{\circ} \mathrm{C}$. The three control groups were as follows: (1) cells without CD44SPIONPs and AMF treatment, as the blank control group;
(2) cells without CD44-SPIONPs and with AMF treatment; and (3) cells with CD44-SPIONPs and without AMF treatment.

\section{Flow Cytometry Analysis}

After incubation for an additional $24 \mathrm{~h}$ in an incubator, the cells were collected at a concentration of $1 \times 10^{6}$ cell $/ \mathrm{mL}$ and washed with cold PBS three times. Then, the cells were stained with $5 \mu \mathrm{l}$ of Annexin V-FITC and $5 \mu \mathrm{L}$ of PI for $15 \mathrm{~min}$ at room temperature in the dark. The cells were analyzed with a flow cytometer (BD Accuri C6 Plus personal flow cytometer, BD, USA). The data were examined using the BD Accuri C6 Plus software (BD, USA). Cells incubated with normal growth medium without AMF treatment were used as control groups.

\section{In Vivo Hyperthermia Therapy}

To prepare the tumor model, $5 \times 10^{7} / 0.1 \mathrm{~mL}$ of Cal-27 cells were subcutaneously injected into the right flanks of the mice. After four days, the mice were randomly divided into four groups with five mice in each group. The tumor volume was calculated using the formula $\mathrm{V}=1 / 2 \mathrm{ab},{ }^{2}$ where "a" represents the major diameter of the tumor $(\mathrm{mm})$ and " $b$ " represents the minor diameter perpendicular to the major diameter ( $\mathrm{mm})$.

The mice were anesthetized with chloral hydrate before treatment. The treatment group was injected at four different points within the tumor with $0.2 \mathrm{~mL}$ of CD44-SPIONPs (100 $\mu \mathrm{g} / \mathrm{mL})$. The mice were subsequently exposed to an AMF with a maximum magnetic intensity of $237 \mathrm{kHz}$ and $50 \mathrm{~A}$ for $30 \mathrm{~min}$ (as Group D). The three control groups were intratumorally injected (1) with $0.2 \mathrm{~mL}$ of physiological saline (as Group A), (2) with $0.2 \mathrm{~mL}$ of CD44-SPIONPs $(100 \mu \mathrm{g} / \mathrm{mL})$ (as Group B), and (3) with $0.2 \mathrm{~mL}$ of physiological saline and exposure to the same AMF (as Group C). Two mice were chosen randomly from each group to detect the real-time intratumoral temperature and rectal temperature by fiber-optic detection.

Two mice were randomly chosen from each group and sacrificed $24 \mathrm{~h}$ after hyperthermia. The tumors were immediately removed and dissected. The resected tumors were fixed in $10 \%$ formalin, embedded in paraffin, sectioned and stained with hematoxylin-eosin. The tumors were then histologically observed.

Other mice were sacrificed after two weeks. The tumor volume was measured to calculate the ratio of inhibition. The Tumor Growth Inhibition value (TGI) $=$ (1-tumor volume of treatment group/tumor volume of control group) $* 100 \%$. 


\section{Statistical Analysis}

All statistical analyses were performed using GraphPad Prism 6 (GraphPad Software Inc., San Diego CA). The sample number for each group was $\geq 3$, and numerical data were reported as the mean $\pm \mathrm{SD}$. P values were considered to be statistically significant at $\mathrm{p}<0.05$.

\section{Results}

\section{Synthesis And Characterization Of CD44-SPIONPs}

XRD patterns of SPIONPs were matched with bulk $\mathrm{Fe}_{3} \mathrm{O}_{4}$ (JCPDS \#: 19-0629), revealing their spinel crystal structure. The magnetic saturation intensity results of SPIONPs and CD44-SPIONPs are shown in Figure 1A. At room temperature, the magnetic saturation strengths of SPIONPs and CD44-SPIONPs were $57 \mathrm{emu} / \mathrm{g} \mathrm{Fe}$ and $23 \mathrm{emu} / \mathrm{g} \mathrm{Fe}$, respectively. In addition, the hysteresis curve passes through the origin, as illustrated in Figure 1B, indicating that when the applied magnetic field is zero, the magnetic saturation intensity of both SPIONPs and CD44-SPIONPs is zero, which means that the hysteresis is zero.

Observation by TEM (Figure 1C) of the CD44SPIONPs thus obtained demonstrated a spherical structure with an average diameter of approximately $100 \mathrm{~nm}$. The DLS distribution (Figure 1D) showed a narrow peak centered at approximately $150 \mathrm{~nm}$ in diameter.

From the temperature-time curve, it can be seen that in the first $25 \mathrm{~min}$, the CD44-SPIONPs slowly increase the temperature under the AMF, after which the temperature remains in a stable range. As shown in Figure 1E, $200 \mu \mathrm{g} /$ $\mathrm{mL}$ CD44-SPIONPs reached a maximum of $64.5^{\circ} \mathrm{C}, 150$ $\mu \mathrm{g} / \mathrm{mL}$ CD44-SPIONPs reached a maximum temperature of approximately $58.1^{\circ} \mathrm{C}, 100 \mu \mathrm{g} / \mathrm{mL}$ CD44-SPIONPs reached a maximum temperature of $50^{\circ} \mathrm{C}$, and $50 \mu \mathrm{g} / \mathrm{mL}$ CD44-SPIONPs reached a maximum of $43.6^{\circ} \mathrm{C}$; for the 0 $\mu \mathrm{g} / \mathrm{mL}$ concentration, the temperature did not rise.

\section{Characterization Of CSCs}

On the second day of culture, a small number of microspheres could be observed. From 4 to 5 days, we observed golf ball-like spheres ranging from 300 to 500 cells per sphere. The middle region was dense due to the large number of cells, and the transmittance was poor. By 7 to 10 days, the cell spheres were irregular in shape. They could be collected for detection or subculture (Figure 2).

Stem cell markers such as Oct4, Sox2, and Nanog are known to form a self-organized core of transcription factors that maintain the pluripotency and self-renewal of human embryonic stem cells. We found that the gene expression of Oct4, Sox2, and Nanog was significantly increased in CSCs compared with that in Cal-27 cells, as observed in Figure 3A.

Western blotting analysis of Cal-27 and CSCs proteins showed that both Cal-27 cells and CSCs have CD44 expression. By gray-scale analysis of protein bands, the expression level of CD44 in CSCs was significantly higher than that in Cal-27 cells $(p<0.05)$, as observed in Figure 3B.

\section{Cytotoxicity Study}

The cytotoxicity of CD44-SPIONPs was evaluated using a CCK8 assay. The cell viability results after $24 \mathrm{~h}$ and $48 \mathrm{~h}$ are shown in Figure 3C. In the range of $0-100 \mu \mathrm{g} / \mathrm{mL}$, there was no significant difference in the survival rate $(p>0.05)$, indicating that CD44-SPIONPs exhibited no negative effect on the growth and proliferation of the CSCs.

\section{Cellular Uptake Of CD44-SPIONPs}

Intracellular "Fe" was detected by Prussian blue staining of CSCs. After incubation with the CD44-SPIONPs, the labeled cells displayed a typical blue color, whereas unlabeled cells did not exhibit blue staining (as shown in Figure 4A).

The uptake and targeting ability of CD44-SPIONPs were investigated in the CSCs, and Cal-27 cells were used as a control group. The subcellular location of CD44-SPIONPs labeled with FITC was studied by utilizing a laser scanning confocal microscope. The CSCs were stained with DAPI to visualize the nucleus so that we could observe the relationship between cells and SPIONPs. The majority of CD44SPIONPs labeled with FITC penetrated the cell membrane into the cytoplasm. In contrast, few CD44-SPIONPs were observed distributed in the cytoplasm of Cal-27 cells, as shown in Figure 4B. These results proved that a large number of CD44-SPIONPs were efficiently internalized by CSCs.

\section{Apoptosis Determination By Annexin V-FITC/PI Staining}

Cell apoptosis was studied by Annexin V-FITC/PI staining and quantified by flow cytometry. For the cells with nanoparticles, compared to the AMFgroup, CD44-SPIONPs induced programmed cell death under AMF. The quantitative results of flow cytometry are shown in Figure 5. After AMF treatment, $44.5 \%$ of cells underwent early apoptosis, and 

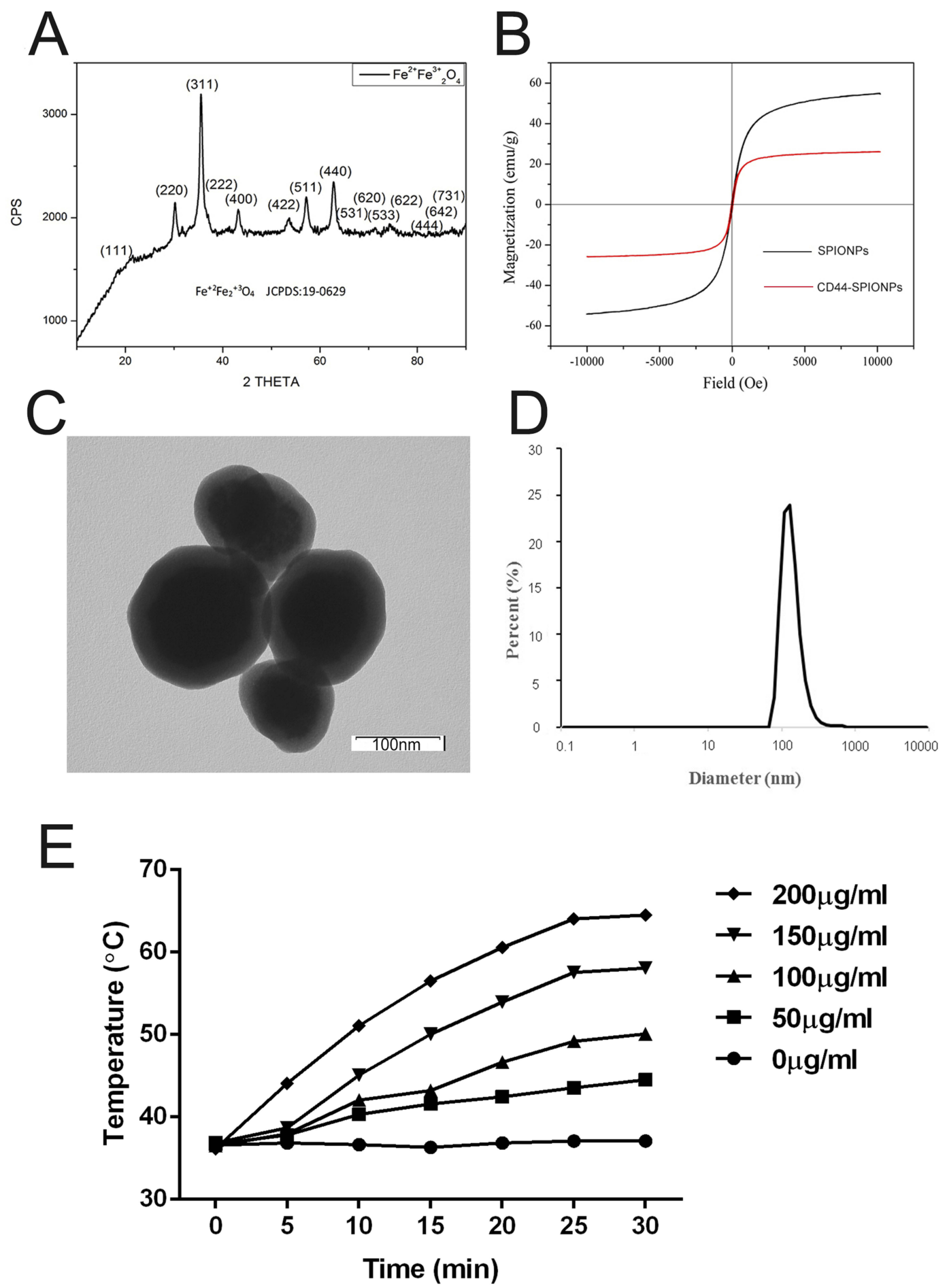

Figure I Characterization of SPIONPs and CD44-SPIONPs. (A) X-ray diffraction pattern of SPIONPs. (B) Magnetization vs magnetic field curves of dry SPIONPs and CD44-SPIONPs at $300 \mathrm{~K}$. (C) Transmission electron microscopic images of nanoparticles $(\times 80,000)$. D: DLS analysis reporting a narrow size distribution centered at 150 $\mathrm{nm}$. (E) The initial temperature was equilibrated to $37^{\circ} \mathrm{C}$, and the temperature of the CD44-SPIONPs dispersion was measured using a fiber-optic temperature sensor following the application of the AMF.

$4.7 \%$ were late apoptotic cells. The apoptotic ratio of the AMF- group was $10 \%$ and $1.5 \%$, respectively. The difference was statistically significant $(p<0.05)$. For the cells without nanoparticles, the quantitative results of the AMF+ group were similar to those of the blank control group $(\mathrm{p}>0.05)$. These results indicated that the CD44-SPIONPs could significantly induce apoptosis in CSCs after AMF treatment. 


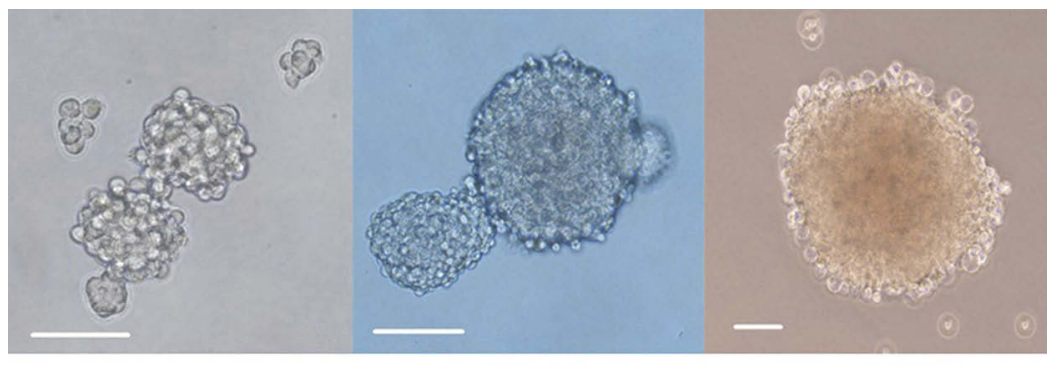

DAY 3

DAY 5

DAY 7

Figure 2 Sphere formation. Representative phase-contrast micrographs of spheres formed by Cal-27 cell lines. Bar: $100 \mu \mathrm{m}$.

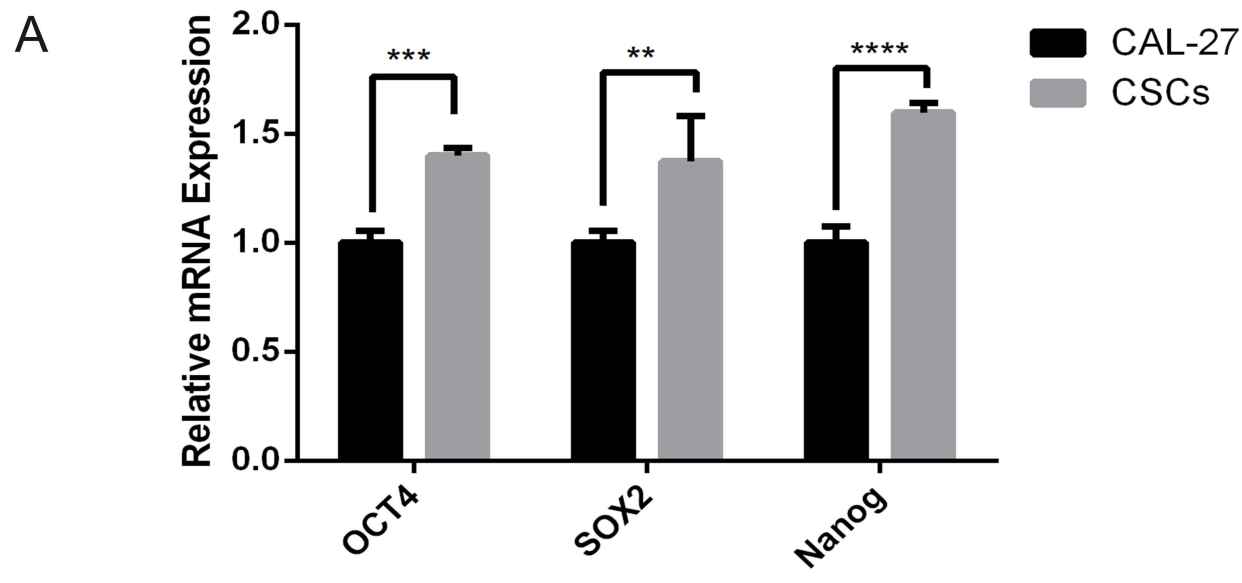

B
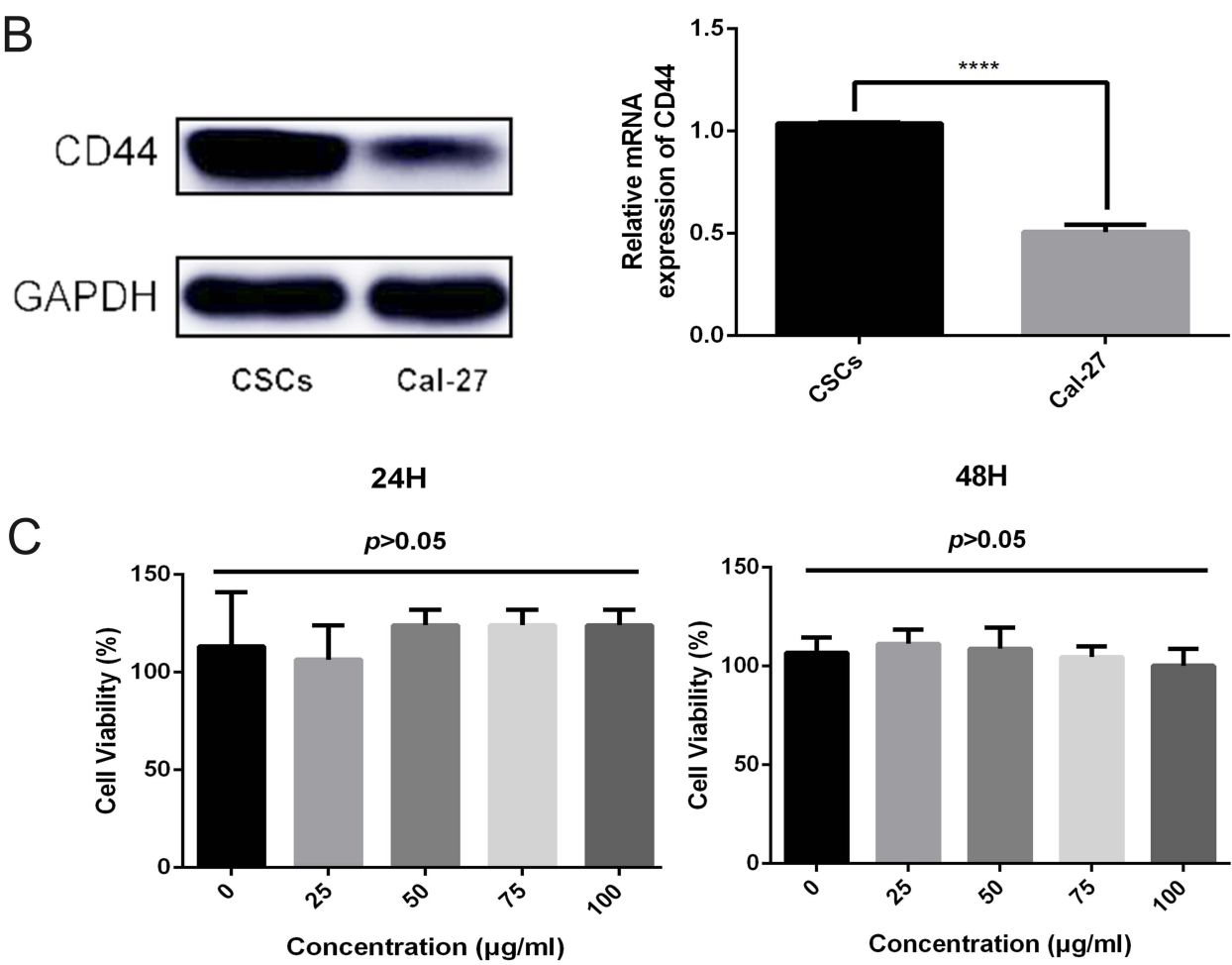

Figure 3 (A) The gene expression of OCT4, SOX2, and NANOG was significantly increased in CSCs compared with that in Cal-27 cells ( $\mathrm{P}<0.05$ ). (B) The relative mRNA level of CD44 is upregulated in CSCs compared with that in Cal-27 cells $(p<0.05)$. (C) Viability of CSCs incubated with different concentrations of CD44-SPIONPs for $24 \mathrm{~h}$ and $48 \mathrm{~h}$, assayed by a CCK8 assy. There was no significant difference in cell viability over the $0-100 \mu g / \mathrm{mL}$ concentration range $(\mathrm{p}>0.05)$. 


\section{A}
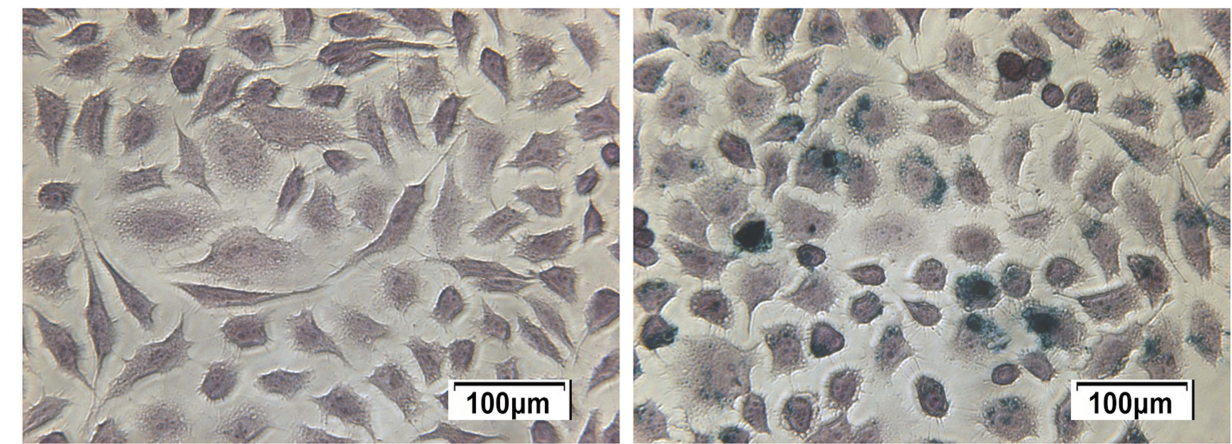

\section{B}
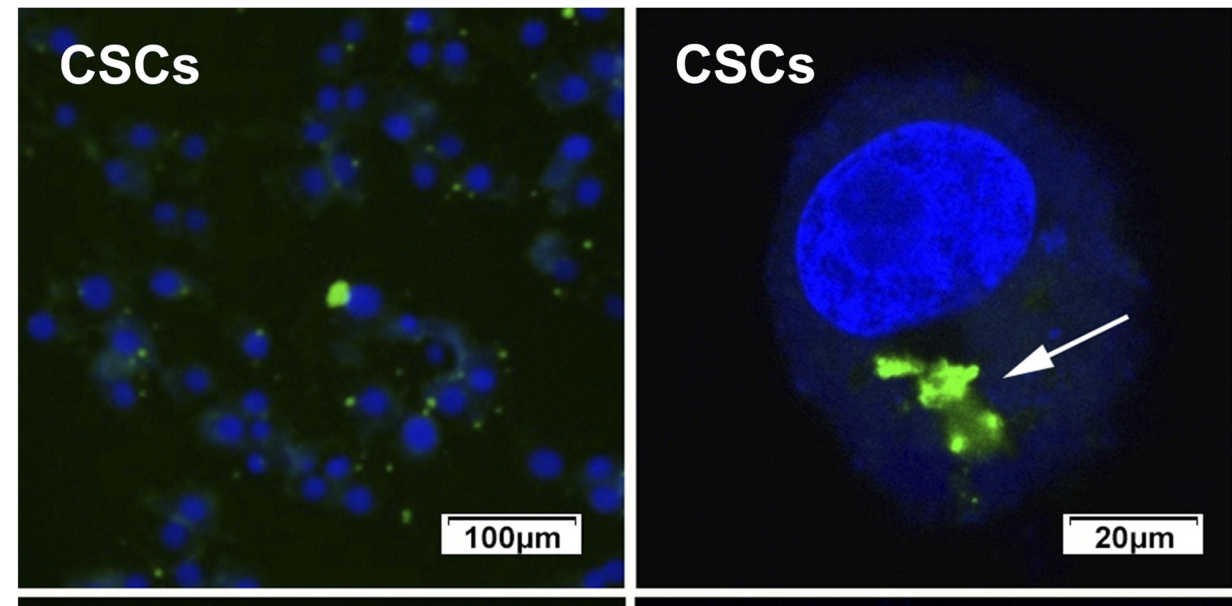

\section{Cal-27}

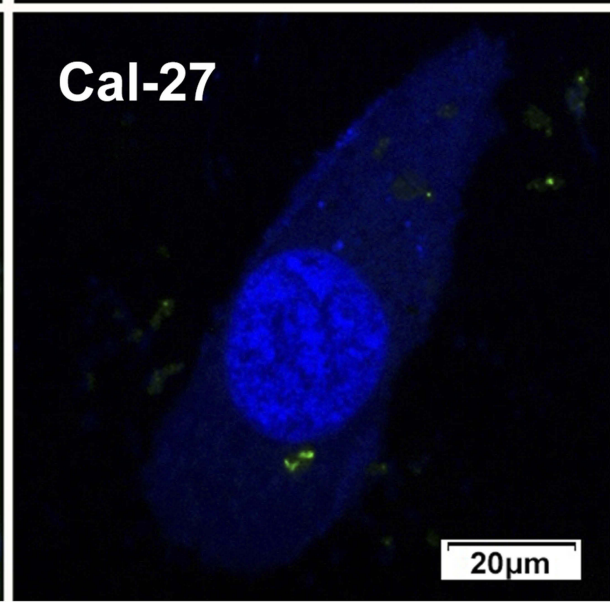

Figure 4 (A) After incubation with the CD44-SPIONPs, the labeled cells displayed the typical blue color, whereas unlabeled cells did not exhibit blue staining. (B) Location and internalization of targeted SPIONPs with Cal-27 cells and CSCs. The cell nucleus was stained with DAPI solution (blue). Location of CD44-SPIONPs after being in contact with CSCs for $24 \mathrm{~h}$; the green fluorescence increased significantly. Arrows show CD44-SPIONPs in endocytic structures. Location of CD44-SPIONPs after being in contact with Cal-27 cells for $24 \mathrm{~h}$; a few nanoparticles entered the cell membrane.

\section{In Vivo Study}

During hyperthermia, the intratumoral temperature of Group D increased to $43^{\circ} \mathrm{C}$ in $10 \mathrm{~min}$ and fluctuated around $43^{\circ} \mathrm{C}$ under an AMF (Figure 6A). The rectal temperature of groups A to D remained steady at approximately $36.5^{\circ} \mathrm{C}$ (Figure 6B).

The tumor volume of the treatment group was smaller than that of the three control groups; the ratios 

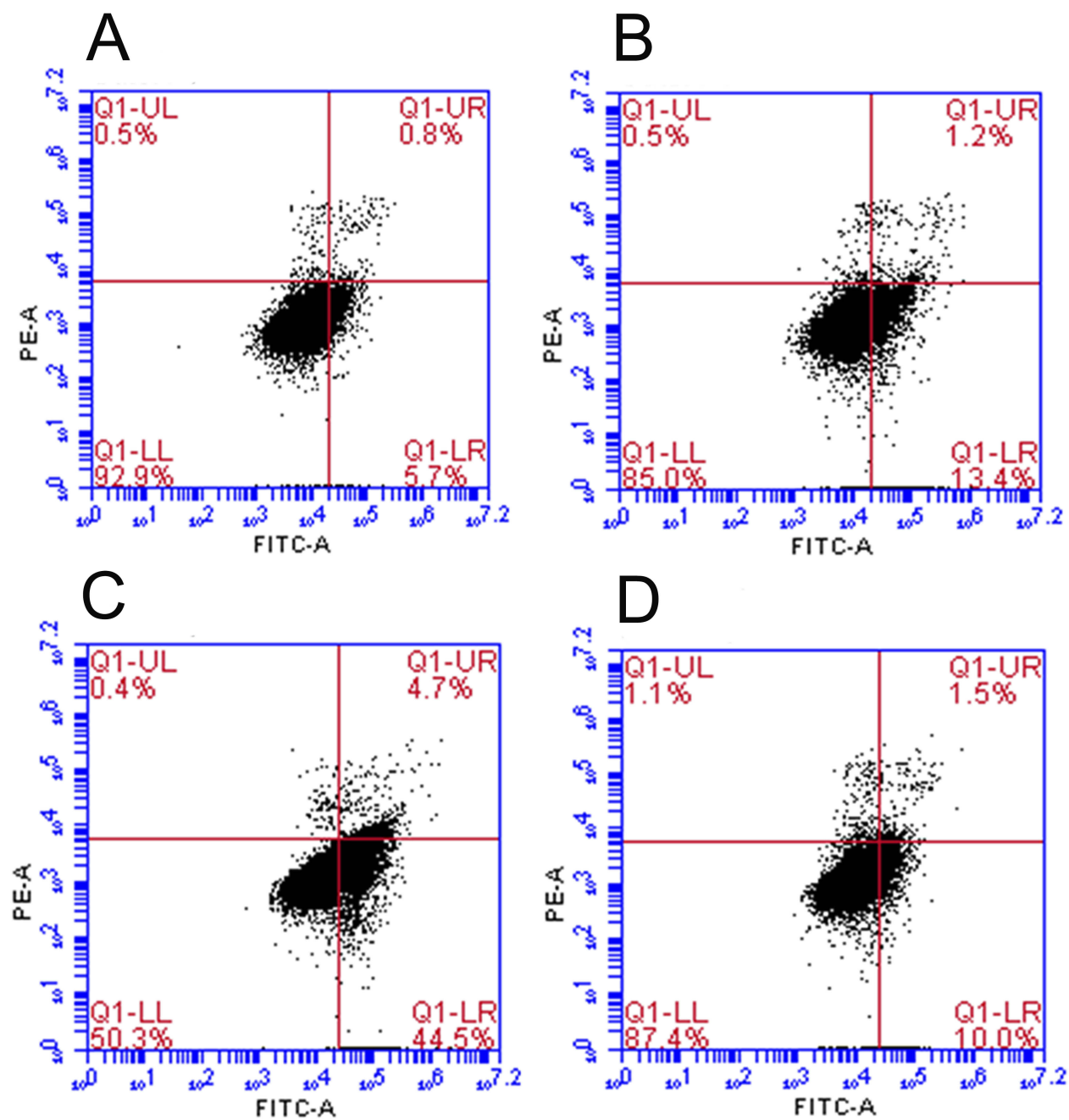

Figure 5 Flow cytometry analysis of CSCs demonstrated that the AMF treatment could induce apoptosis in CSCs. (A) cells without CD44-SPIONPs and AMF treatment, as the blank control group; (B) cells without CD44-SPIONPs and with AMF treatment; (C) cells with CD44-SPIONPs and AMF treatment; (D) cells with CD44-SPIONPs and without AMF treatment.

of inhibition were all above $33 \%(\mathrm{P}<0.05)$. The tumor volumes of the grafted tumors are shown in Table 1.

\section{Histological Analysis}

Following hyperthermia, in Group D, a large number of apoptotic tumor cells with the characteristics of karyopyknosis and condensation were discovered. Acidophilia increased, and the normal cell structure disappeared. Hemorrhagic lesions were detected in certain apoptotic and necrotic areas. The magnetic fluid was distributed between the apoptotic and necrotic areas.

In the control groups, the nucleoli were stained, and karyokinesis was occasionally detected. There were a few ischemic necrotic tissues observed in the center, and scattered nanoparticles were observed between the tumor tissues in Group B, as shown in Figure 6C.

\section{Discussion}

Compared with other treatment methods, tumor thermotherapy has the following characteristics. First, in vivo and in vitro studies have confirmed that tumor cells are more sensitive to heat than normal cells, especially in the center of the tumor, which is in a state of low nutrition and hypoxia. Second, the blood vessels in the tumor have no innervation; thus, the resistance of blood flow in tumor tissue is large, resulting in a slow blood flow speed. Thus, the effectiveness of blood circulation is far lower than that of normal tissue, which makes the tumor more likely to 

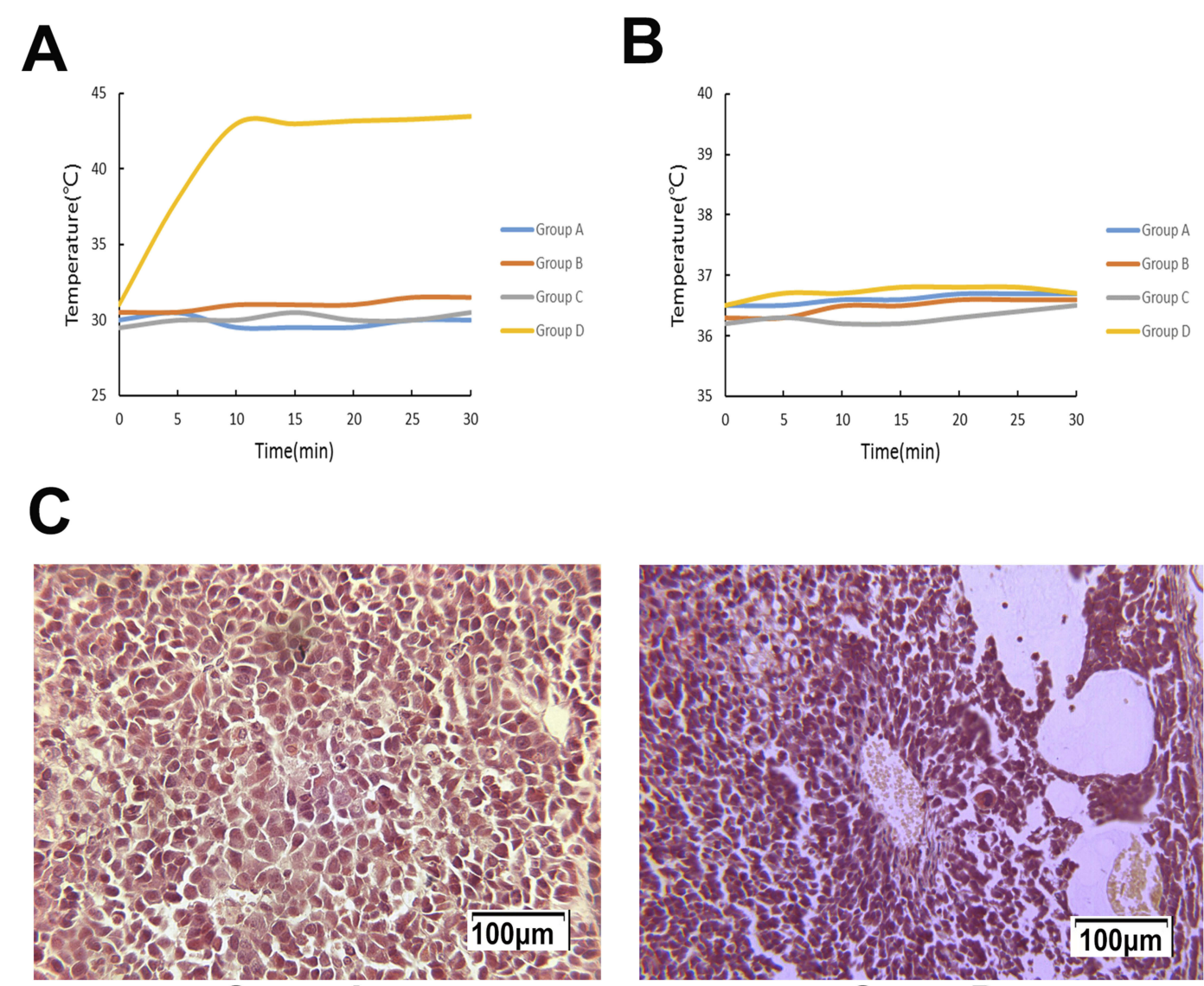

Group A

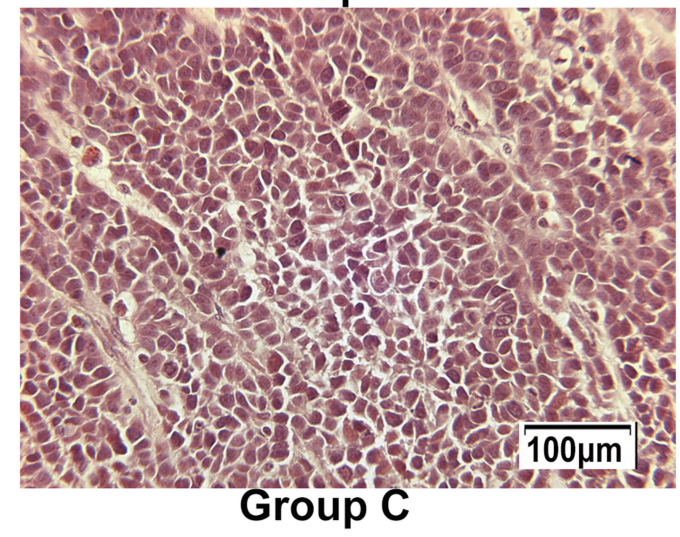

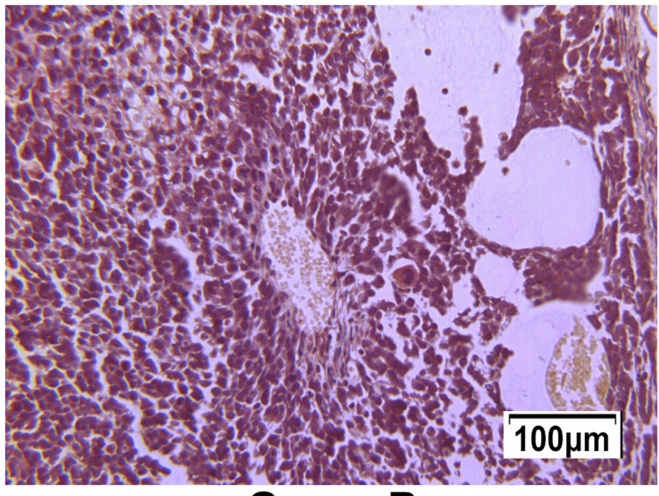

Group B

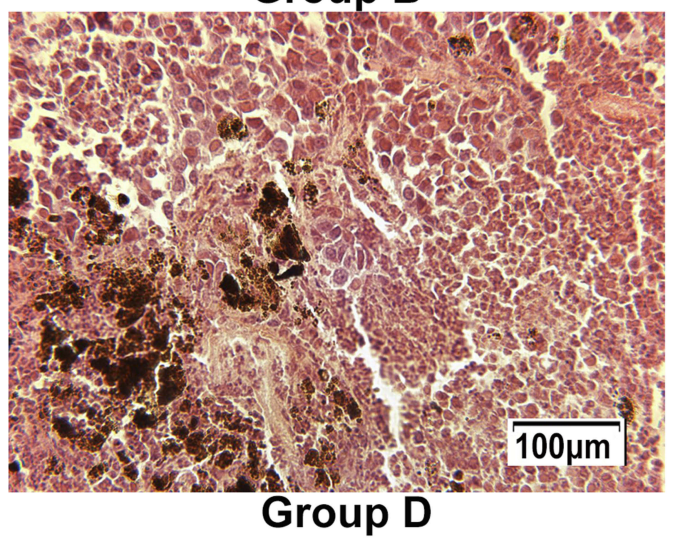

Figure 6 (A) Intratumoral temperature during AMF treatment. (B) Rectal temperature during AMF treatment. (C) The magnetic fluid is distributed between the apoptotic and necrotic areas, with a significant number of apoptotic and coagulative necrotic tumor cells in certain areas following hyperthermia.

accumulate heat and more susceptible to temperature. When heated, the temperature of the tumor area is $3-7^{\circ} \mathrm{C}$ higher than that of the surrounding normal tissues. ${ }^{27,28}$ Therefore, at the time of treatment, the central part of the tumor can be heated to above $43^{\circ} \mathrm{C}$ to induce degeneration and necrosis of the cells, and damage to normal tissues surrounding the tumor can be avoided. Moreover, thermotherapy can also inhibit the synthesis of DNA and RNA in tumor cells and can cause denaturation of essential proteins for cell proliferation, thereby inhibiting the proliferation process of tumor cells and increasing the lethality of the treatment for tumor cells. ${ }^{29}$

Many cell lines were derived from cancer stem-like cells, which were isolated in standard culture media without epidermal growth factor or a fibroblast feeder layer to avoid obtaining clones of more differentiated cells. ${ }^{30}$ However, in 
Table I The Tumor Growth Inhibition Value Of Cancer In Nude Mice Following Treatment

\begin{tabular}{|l|l|l|}
\hline Groups & $\begin{array}{l}\text { Tumor Volume, Mean } \\
\mathbf{m m}^{\mathbf{3}} \pm \mathbf{s}\end{array}$ & $\begin{array}{l}\text { Volume Inhibitory } \\
\text { Rate, } \%\end{array}$ \\
\hline A & $685 \pm 92$ & - \\
B & $625 \pm 102$ & $8.76^{\mathrm{a}}$ \\
C & $680 \pm 85$ & $0.73^{\mathrm{a}}$ \\
D & $456 \pm 64$ & $33.43^{\mathrm{b}}$ \\
\hline
\end{tabular}

Notes: ${ }^{\mathrm{a}} \mathrm{P}>0.05$ and ${ }^{\mathrm{b}} \mathrm{P}<0.05$ vs $\mathrm{A}$ group. A: injected with physiological saline; $\mathrm{B}$ injected with CD44-SPIONPs; C: injected with physiological saline and treated with magnetic field; D: injected with CD44-SPIONPs and treated with magnetic field.

the later cultivation process, cells will inevitably differentiate, resulting in the heterogeneity of tumor cell lines. Some cells with self-renewal capacity become stem cell-like cells, which can be separated from normal cells by 3D spheroid culture. ${ }^{31-33}$ Cancer cells require higher serum levels and are adherent in culture medium, while CSCs are highly dependent on growth factors. Suspension culture is carried out in serum-free medium containing epidermal growth factors, in which only stem cells with self-renewal ability can proliferate and form cell spheres, while non-stem cells gradually undergo necrosis. At present, 3D spheroid culture technology has become a common method for studying CSCs. ${ }^{23}$

Superparamagnetic $\mathrm{Fe}_{4} \mathrm{O}_{3}$ particles are magnetic nanomaterials with broad application prospects in biomedical fields. The preparation method is relatively simple, and the raw materials are easy to obtain. In our experiment, $\mathrm{Fe}_{4} \mathrm{O}_{3}$ particles were obtained by coprecipitation and reacted with carboxymethyl dextran to obtain a carboxyl terminal (-COOH), and an amide bond (-CO-NH-) was covalently coupled with the amino terminus (-NH2) of the CD44 antibody. Biosafety evaluation of the CD44-SPIONPs showed good biocompatibility.

In recent years, some studies have confirmed that CD44positive cells account for less than $10 \%$ of all head and neck tumor cells, but these cells have a strong ability to clone and self-renew, as well as the ability to initiate tumors. ${ }^{15} \mathrm{CD} 44$ on the surface of many cells is in a relatively static state, while CD44 on the surface of CSCs is in an overexpression state, which can bind to its ligand, leading to the immune escape of cancer cells, and can promote the occurrence, development, invasion and metastasis of tumors. ${ }^{17,34}$ Western blot results showed that CSCs overexpressed CD44 compared to Cal-27 cells. Therefore, we selected the CD44 antibody receptor on the surface of CSCs as a target and labeled the CD44 antibody with FITC fluorescence. After coculture with cells, it was observed by confocal microscopy that CD44-SPIONPs penetrated into the cytoplasm through the cell membrane.
Furthermore, the in vivo results in this study also prove that magnetic fluid hyperthermia can inhibit the growth of grafted tumors in mice. These results are important in light of the clinical use of CD44-SPIONP-mediated hyperthermia therapy for head and neck squamous cell carcinoma.

\section{Conclusion}

Our experiments confirmed that it is possible to kill CSCs using targeted magnetic nanoparticles and an AMF. We have demonstrated that nanoparticles can penetrate the cell membrane, enter the interior of the cells, and significantly reduce cell viability by heating in a magnetic field, leading to programmed cell death. Magnetic fluid hyperthermia is able to significantly inhibit grafted tumor growth in the Cal-27 mouse model. These observations offer a promising strategy for using targeted magnetic nanoparticles to treat cancers and reduce metastasis. However, more studies are needed to optimize the regimens in further applications.

\section{Acknowledgments}

This research was supported by the Shandong Province Science and Technology Development Project (2015GSF118151).

\section{Disclosure}

The authors report no conflicts of interest in this work.

\section{References}

1. Chen L, Hu CS, Chen XZ, et al. Concurrent chemoradiotherapy plus adjuvant chemotherapy versus concurrent chemoradiotherapy alone in patients with locoregionally advanced nasopharyngeal carcinoma: a phase 3 multicentre randomised controlled trial. Lancet Oncol. 2012;13(2):163-171. doi:10.1016/S1470-2045(11)70320-5

2. Chua DT, Sham JS, Au GK, Choy D. Concomitant chemoirradiation for stage III-IV nasopharyngeal carcinoma in Chinese patients: results of a matched cohort analysis. Int J Radiat Oncol Biol Phys. 2002;53 (2):334-343. doi:10.1016/s0360-3016(02)02710-4

3. Krishnamurthy S, Nör JE. Head and neck cancer stem cells. J Dent Res. 2012;91(4):334-340. doi:10.1177/0022034511423393

4. Sayed SI, Dwivedi RC, Katna R, et al. Implications of understanding cancer stem cell (CSC) biology in head and neck squamous cell cancer. Oral Oncol. 2011;47(4):237-243. doi:10.1016/j.oraloncology.2011.02.009

5. Krishnamurthy S, Dong Z, Vodopyanov D, et al. Endothelial cellinitiated signaling promotes the survival and self-renewal of cancer stem cells. Cancer Res. 2010;70(23):9969-9978. doi:10.1158/00085472.CAN-10-1712

6. Zhao Y, Bao Q, Schwarz B, et al. Stem cell-like side populations in esophageal cancer: a source of chemotherapy resistance and metastases. Stem Cells Dev. 2014;23(2):180-192. doi:10.1089/scd.2013.0103

7. Fang DD, Cao J, Jani JP, et al. Combined gemcitabine and CHK1 inhibitor treatment induces apoptosis resistance in cancer stem celllike cells enriched with tumor spheroids from a non-small cell lung cancer cell line. Front Med-Prc. 2013;7(4):462-476. doi:10.1007/ s11684-013-0270-6 
8. Campos MS, Neiva KG, Meyers KA, Krishnamurthy S, Nör JE. Endothelial derived factors inhibit anoikis of head and neck cancer stem cells. Oral Oncol. 2012;48(1):26-32. doi:10.1016/j. oraloncology.2011.09.010

9. Burke AR, Singh RN, Carroll DL, et al. The resistance of breast cancer stem cells to conventional hyperthermia and their sensitivity to nanoparticle-mediated photothermal therapy. Biomaterials. 2012;33(10):2961-2970. doi:10.1016/j.biomaterials.2011.12.052

10. Kobayashi T. Cancer hyperthermia using magnetic nanoparticles. Biotechnol J. 2011;6(11):1342-1347. doi:10.1002/biot.201100045

11. Sadhukha T, Niu L, Wiedmann TS, Panyam J. Effective elimination of cancer stem cells by magnetic hyperthermia. Mol Pharmaceut. 2013;10(4):1432-1441. doi:10.1021/mp400015b

12. Kaseb HO, Fohrer-Ting H, Lewis DW, Lagasse E, Gollin SM. Identification, expansion and characterization of cancer cells with stem cell properties from head and neck squamous cell carcinomas. Exp Cell Res. 2016;348(1):75-86. doi:10.1016/j.yexcr.2016.09.003

13. Bourguignon LYW, Earle C, Shiina M. Activation of matrix hyaluronan-mediated CD44 signaling, epigenetic regulation and chemoresistance in head and neck cancer stem cells. Int J Mol Sci. 2017;18 (9): 1849. doi:10.3390/ijms 18091849

14. Li C, Heidt DG, Dalerba P, et al. Identification of pancreatic cancer stem cells. Cancer Res. 2007;67(3):1030-1037. doi:10.1158/00085472.CAN-06-2030

15. Prince ME, Sivanandan R, Kaczorowski A, et al. Identification of a subpopulation of cells with cancer stem cell properties in head and neck squamous cell carcinoma. Proc Natl Acad Sci U S A. 2007;104 (3):973-978. doi:10.1073/pnas.0610117104

16. Endo K, Terada T. Protein expression of CD44 (standard and variant isoforms) in hepatocellular carcinoma: relationships with tumor grade, clinicopathologic parameters, p53 expression, and patient survival. J Hepatol. 2000;32(1):78-84. doi:10.1016/s0168-8278(00) 80192-0

17. Okamoto A, Chikamatsu K, Sakakura K, Hatsushika K, Takahashi G, Masuyama K. Expansion and characterization of cancer stem-like cells in squamous cell carcinoma of the head and neck. Oral Oncol. 2009;45(7):633-639. doi:10.1016/j.oraloncology.2008.10.003

18. Creixell M, Bohórquez AC, Torres-Lugo M, Rinaldi C. EGFR-targeted magnetic nanoparticle heaters kill cancer cells without a perceptible temperature rise. ACS Nano. 2011;5(9):7124-7129. doi: $10.1021 / \mathrm{nn} 201822 \mathrm{~b}$

19. Shen $\mathrm{Y}, \mathrm{Wu} \mathrm{C}$, Uyeda TQP, et al. Elongated nanoparticle aggregates in cancer cells for mechanical destruction with low frequency rotating magnetic field. Theranostics. 2017;7(6):1735-1748. doi:10.7150/ thno. 18352

20. Shevtsov MA, Nikolaev BP, Yakovleva LY, et al. Superparamagnetic iron oxide nanoparticles conjugated with epidermal growth factor (SPION-EGF) for targeting brain tumors. Int $J$ Nanomedicine. 2014;9:273-287. doi:10.2147/IJN.S55118
21. Zhu LL, Zhang Z, Jiang HS, Chen H, Chen Y, Dai YT. Superparamagnetic iron oxide nanoparticle targeting of adipose tissuederived stem cells in diabetes-associated erectile dysfunction. Asian $J$ Androl. 2017;19(4):425-432. doi:10.4103/1008-682X.179532

22. Lim YC, Oh S, Cha YY, Kim S, Jin X, Kim H. Cancer stem cell traits in squamospheres derived from primary head and neck squamous cell carcinomas. Oral Oncol. 2011;47(2):83-91. doi:10.1016/j.oraloncology.2010.11.011

23. Qiu X, Wang Z, Li Y, Miao Y, Ren Y, Luan Y. Characterization of sphere-forming cells with stem-like properties from the small cell lung cancer cell line H446. Cancer Lett. 2012;323(2):161-170. doi:10.1016/j.canlet.2012.04.004

24. Fu T, Hsieh I, Cheng J, et al. Association of OCT4, SOX2, and NANOG expression with oral squamous cell carcinoma progression. J Oral Pathol Med. 2016;45(2):89-95. doi:10.1111/jop.12335

25. Guo X, Li W, Luo L, et al. External magnetic field-enhanced chemophotothermal combination tumor therapy via iron oxide nanoparticles. Acs Appl Mater Inter. 2017;9(19):16581-16593. doi:10.1021/ acsami.6b16513

26. Creixell M, Herrera AP, Ayala V, et al. Preparation of epidermal growth factor (EGF) conjugated iron oxide nanoparticles and their internalization into colon cancer cells. J Magn Magn Mater. 2010;322(15):2244-2250. doi:10.1016/j.jmmm.2010.02.019

27. Kruse AM, Meenach SA, Anderson KW, Hilt JZ. Synthesis and characterization of CREKA-conjugated iron oxide nanoparticles for hyperthermia applications. Acta Biomater. 2014;10(6):2622-2629. doi:10.1016/j.actbio.2014.01.025

28. Chen Q, Ke H, Dai Z, Liu Z. Nanoscale theranostics for physical stimulus-responsive cancer therapies. Biomaterials. 2015;73:214230. doi:10.1016/j.biomaterials.2015.09.018

29. Wust P, Hildebrandt B, Sreenivasa G, et al. Hyperthermia in combined treatment of cancer. Lancet Oncol. 2002;3(8):487-497.

30. Gioanni J, Fischel JL, Lambert JC, et al. Two new human tumor cell lines derived from squamous cell carcinomas of the tongue: establishment, characterization and response to cytotoxic treatment. Eur $J$ Cancer Clin Oncol. 1988;24(9):1445-1455.

31. Akbarzadeh M, Maroufi NF, Tazehkand AP, et al. Current approaches in identification and isolation of cancer stem cells. $J$ Cell Physiol. 2019;234(9):14759-14772. doi:10.1002/jcp.28271

32. Shrivastava S, Steele R, Sowadski M, Crawford SE, Varvares M, Ray RB. Identification of molecular signature of head and neck cancer stem-like cells. Sci Rep-Uk. 2015;5(1).

33. Setoguchi T, Taga T, Kondo T. Cancer stem cells persist in many cancer cell lines. Cell Cycle. 2004;3(4):414-415. doi:10.4161/ cc.3.4.799

34. Zhang P, Zhang Y, Mao L, Zhang Z, Chen W. Side population in oral squamous cell carcinoma possesses tumor stem cell phenotypes. Cancer Lett. 2009;277(2):227-234. doi:10.1016/j.canlet.2008.12.015
International Journal of Nanomedicine

\section{Publish your work in this journal}

The International Journal of Nanomedicine is an international, peerreviewed journal focusing on the application of nanotechnology in diagnostics, therapeutics, and drug delivery systems throughout the biomedical field. This journal is indexed on PubMed Central, MedLine, CAS, SciSearch ${ }^{\mathbb{R}}$, Current Contents ${ }^{\mathbb{R}} /$ Clinical Medicine, $^{2}$
Journal Citation Reports/Science Edition, EMBase, Scopus and the Elsevier Bibliographic databases. The manuscript management system is completely online and includes a very quick and fair peer-review system, which is all easy to use. Visit http://www.dovepress.com/ testimonials.php to read real quotes from published authors. 